\title{
Epidemiology and outcome of cervical cancer in national institute of Morocco
}

Sanaa Elmajjaoui ${ }^{1 \dagger}$, Nabil Ismaili ${ }^{*^{*}+}$, Hanane El Kacemi ${ }^{1}$, Tayeb Kebdani ${ }^{1}$, Hassan Sifat ${ }^{3}$ and Noureddine Benjaafar ${ }^{1}$

\begin{abstract}
Background: On behalf of the medical staff of the National Institute of Oncology of Rabat, we conducted a retrospective study to report epidemiology and 5-year outcomes of cervical carcinoma in Moroccan women.

Methods: We reviewed all women diagnosed with invasive cervical carcinoma in our institute between January 2006 and December 2006. Outcomes and prognoses are analyzed in patients who received at least one treatment.

Results: The analysis included 646 women. Median age was 50 years (23-85 years). Bleeding was the most frequent symptom (95\%). The most predominant histology was squamous cell carcinoma (94\%). The majority of patients were diagnosed at locally advanced stages (88\%). Among patients who received treatment $(n=550)$, the management was based on concurrent chemoradiotherapy in $69.7 \%$ of cases. The median duration of follow-up was 60 months (range 2-78 months). Overall survival, progression free survival, and locoregional recurrence free survival were 63.2, 60.7 and $79.1 \%$ respectively. Significant poor prognostic factors in univariate analysis included stage, tumor size, lymph node involvement, anemia and absence of response to radiotherapy. The prognostic significance of response to radiotherapy and stage were retained in multivariate analysis.

Conclusion: Cervical cancer in our Institute is diagnosed at locally advanced stages. Two third of patients were treated by concurrent chemoradiotherapy. Outcome of Moroccan patients are comparable to that of western countries. Significant prognostic factors were stage, tumor size, lymph node involvement, anemia, and response to radiotherapy. The way to reduce the global burden of cervical cancer in our country continues to be the development of vaccination and screening programs.
\end{abstract}

Keywords: Cervical cancer, Epidemiology, Treatments, Outcomes

\section{Background}

Cervical cancer is the third most common cancer and the fourth leading cause of cancer death in females in the world, accounting for $9 \%(529,800)$ of the new cancer cases and $8 \%(275,100)$ of the cancer deaths among females in 2008 [1, 2]. Its incidence has remarkably decreased in western countries through organized screening programs [3]. However, in Africa, in general, and in Morocco especially, cervical cancer represents a major health problem and the leading cause of cancer death in women because of the diagnosis at advanced stages [1]. In Moroccan women, cervical cancer is the second most common cancer after breast cancer [4]. The incidences of cervical cancer in Casablanca and Rabat were 14.4/ 100000 (new cases per 100000 women) and 13/100000, respectively.

The aim of our study was to assessing the current outcomes after a diagnosis of cervical cancer since 2005 when campaigns to improve prevention and treatment were launched by the efforts of the government and of the Lalla Salma Foundation Prevention and Treatment of Cancers. In a previous investigation of cervical cancer in young Moroccan women, treated between 1980 and 1990,overall survival rate was only $41 \%$ at 5 years [5]. Our hypothesis is that the outcomes of cervical cancer were improved as compared to previous data.

\footnotetext{
* Correspondence: ismailinabil@yahoo.fr

${ }^{\dagger}$ Equal contributors

${ }^{2}$ Medical Oncology, Cheikh Khalifa Ibn Zaid Hospital, Université Mohammed

VI des Sciences de la Santé, Casablanca, Morocco

Full list of author information is available at the end of the article
}

\section{$\int$ Biomed Central}

(c) 2016 Elmajjaoui et al. Open Access This article is distributed under the terms of the Creative Commons Attribution 4.0 International License (http://creativecommons.org/licenses/by/4.0/), which permits unrestricted use, distribution, and reproduction in any medium, provided you give appropriate credit to the original author(s) and the source, provide a link to the Creative Commons license, and indicate if changes were made. The Creative Commons Public Domain Dedication waiver (http://creativecommons.org/publicdomain/zero/1.0/) applies to the data made available in this article, unless otherwise stated. 


\section{Methods}

\section{Study design}

We retrospectively investigated women of all ages withsquamous-cell carcinoma, adenocarcinoma, or adenosquamous carcinoma of the cervix of International Federation of Gynecology and Obstetrics (FIGO 2002) stages I, stage II, stage III of stage IV (Additional file 1, page 1). Women were excluded from the study if they met any of the following criteria: lack of pathological confirmation of invasive carcinoma; and in situ cervical cancers.

All women diagnosed with invasive cervical carcinoma, between January 2006 and December 2006, were included. In 2006, Morocco had only two cancer centers, the most important was National Institute of Oncology of Rabat which includes mainly patients coming from northern and eastern regions of Morocco, the second was Casablanca cancer center which include mainly patients coming from southern regions of Morocco. So the population included in our series is representative of the general population of our country.

The ethical approval for the study was obtained from our ethics committee; the National Institute of Oncology ethics committee. Written informed consent was not required, however all patients provided there oral consent. The ethics committee approved the verbal informed consent procedure.

Patient's medical records were reviewed for investigations of demographic characteristics, clinical signs, clinical sage, histological results, and outcomes. Biological work-ups were analyzed. Radiological reports were reviewed to determine the stage of the disease caused by the invasive carcinoma. Data concerning treatment modalities, CCRT, RT, Surgery, adjuvant treatments (CCRT, RT, brachytherapy), preoperative treatments, and palliative treatments (radiotherapy and chemotherapy), were collected and analyzed.

During radiotherapy treatment, patients were evaluated weekly by clinical examination. During concurrent chemo-radiotherapy, patients were evaluated weekly by clinical examination, a complete blood count and serum levels ofcreatinine. Patients had a pelvic examination under anesthesia at the time of each intra-cavity treatment (brachytherapy). During palliative, neo-adjuvant or adjuvant chemotherapy, patients were evaluated every 3 weekly by clinical examination, complete blood count and serum levels of creatinine. Once the treatment ended, patients were evaluated every 3 months for the first 2 years, every 6 months during the third, fourth and fifth years, and then annually. Disease status was assessed by history taking, physical examination, and appropriate laboratory and radiologic tests. Safety was assessed at the time of each evaluation with the use Cooperative Group Common Toxicity Criteria.

We analyzed the outcome of patients treated in our institute and the impact of certain prognostic factors on survival: stage of the disease, tumor size, lymph node involvement, anemia, and response to radiotherapy. These factors were chosen because they affect the survival of patients diagnosed with cervical carcinoma.

\section{Statistical analysis}

Loco-regional recurrence free survival (LRRFS) (locoregional events occurred in the cervix and/or regional lymph nodes, with or without concurrent metastatic recurrence) was calculated from the date of diagnosis (biopsy) to the date of first documented locoregional relapse. Progression free survival (PFS) was calculated from the date of diagnosis (biopsy) tothe date of the first physical or radiographic evidence of disease progression, death or the last follow-up visit. Overall survival (OS) was calculated from the date of diagnosis (biopsy) to the date of death or the last follow-up visit. Kaplan-Meier method was used to estimate the rates of 5 years LRRFS, PFS, and OS. Log-rank-test was used to evaluate the differences between the groups [6].

Univariate and multivariate Cox proportional hazard regression models analyses were used to evaluate the relationship between survival (LRRFS, PFS, and OS), and prognostic factors (age, histology, stage of disease, lymph node involvement, tumor volume, response to treatment, and anemia) [7]. Candidate prognostic factors for LRRFS, PFS, and OS, with a 0.5 level of significance in univariate analysis were entered in a multivariate Cox model. Statistical evaluation was carried out using SPSS 17.0 statistical software.

Patients lost to follow up before to receive at least one treatment modality [CCRT, exclusive RT, Surgery, brachytherapy, and palliative treatments (radiotherapy and chemotherapy)] were excluded from efficacy and safety analyses (96 women). Patients lost to follow up during the treatment or the follow up period were censored.

\section{Study endpoints}

The study endpoints include: the analysis of epidemiological characteristics, evaluation of 5-year outcomes (loco-regional control, progression free survival, and overall survival), and analysis of prognostic factors.

Treatment of cancers in Morocco has significantly evolved the last decade through the efforts of the government and of the Lalla Salma Foundation Prevention and Treatment of Cancers. Our hypothesis is that the outcomes of patients with cervical cancer were improved.

\section{Results}

From January 2006 to December 2006, 646 patients were enrolled. All of them were included in the epidemiological analyzes of demographic and clinical characteristics. Patients who did not receive any treatment were excluded from efficacy and safety analyses. 


\section{Patient and tumor characteristics (Tables 1 and 2)}

Median age was 50 years (range 23-85 years). Median duration of evolution of symptoms (from onset of symptoms to consultation at our center) was 5 months (range: 1-48 months). Bleeding was the most common symptom showed in $95 \%$ of cases, followed by leukorrhea (50.2\%).

Squamous cell carcinoma (SCC) histology was the most common pathological type and was reported in $94 \%$ of cases followed by adenocarcinoma in $5.5 \%$ of cases. Only $0.5 \%$ of cases have adenosquamous carcinoma. Tumor size was equal or greater than $4 \mathrm{~cm}$ in $81 \%$ of cases with a median tumor size of $7 \mathrm{~cm}$. Patients have locally advanced stages (IB2, II, III and IV), according to FIGO 2002 staging system, in $88 \%$ of the cases. External iliac, internal iliac and para-aortic lymph nodes were observed in 96 cases (15\%), 70 cases (10.8\%), and 45 cases $(7 \%)$, respectively, and they were most often associated. Only fourteen patients were metastatic at presentation $(2.2 \%)$.

Table 1 Demographic characteristics for all patients included $(n=646)$

\begin{tabular}{|c|c|}
\hline Characteristics & Patients number (\%) \\
\hline \multicolumn{2}{|l|}{ Age } \\
\hline Median & 50 years \\
\hline Range & $23-85$ years \\
\hline \multicolumn{2}{|l|}{ Age intervals } \\
\hline $15-24$ years & $1(0.2 \%)$ \\
\hline $25-34$ years & $41(6.3 \%)$ \\
\hline $35-44$ years & $172(26.6 \%)$ \\
\hline $45-54$ years & 197 (30.5\%) \\
\hline $55-64$ years & $136(21.1 \%)$ \\
\hline $65-74$ years & $73(11.3 \%)$ \\
\hline$>75$ years & $26(4 \%)$ \\
\hline \multicolumn{2}{|l|}{ Menopausalstatus } \\
\hline Menopausal & $343(53 \%)$ \\
\hline Premenopausal & $303(47 \%)$ \\
\hline \multicolumn{2}{|l|}{ Marital status } \\
\hline Single & $33(5 \%)$ \\
\hline Maried & $517(80 \%)$ \\
\hline ND & $96(15 \%)$ \\
\hline \multicolumn{2}{|c|}{ Age at first marriage } \\
\hline$<20$ years & 381 (59 \%) \\
\hline$>20$ years & $265(41 \%)$ \\
\hline \multicolumn{2}{|l|}{ Number of parities } \\
\hline 0 & $27(4.2 \%)$ \\
\hline$<4$ & $178(27.5 \%)$ \\
\hline$>=4$ & 407 (63\%) \\
\hline ND & $34(5.3 \%)$ \\
\hline
\end{tabular}

Abreviations: ND not defined
Table 2 Findings on clinical examination

\begin{tabular}{ll}
\hline Clinical examination & Number of patients (\%) \\
\hline Performance status & $530(82 \%)$ \\
PS 1 & $110(17 \%)$ \\
PS 2 & $6(1 \%)$ \\
PS 3 & \\
Tumor size & $72(11 \%)$ \\
$<4$ cm & $574(89 \%)$ \\
$\geq 4$ cm & \\
State of the vagina & $133(20.6 \%)$ \\
Not invaded & $513(79.4 \%)$ \\
Invaded & $263(40.7 \%)$ \\
Upper third & $196(30.3 \%)$ \\
Middle third & $54(8.4 \%)$ \\
Lower third & \\
State of parameters & $137(21.2 \%)$ \\
Not invaded & $509(78.8 \%)$ \\
Invaded & $86(13.3 \%)$ \\
Proximal & $161(25 \%)$ \\
Distal & $262(40.5 \%)$ \\
Until the wall & $13(2 \%)$ \\
Clinical stage & \\
IA & $14(2.2 \%)$ \\
IV1 &
\end{tabular}

Treatment modalities (Fig. 1) $(n=550)$

Among 646 patients, the treatment has not been done in 96 cases $(14.6 \%)$. These patients were lost to follow-up before the initiation of management and were excluded from efficacy analyses. This is largely explained by the socio-economic level, often poor in our population.

Three hundred eighty three patients (69.7 \%) underwent curative CCRT. Among these patients, 17 received adjuvant surgery. Seven cases have complete pathological response in surgical specimens. Exclusive radiotherapy was indicated in 49 patients (8.9\%), only one patient received adjuvant surgery (staged IIA with a size of $3.5 \mathrm{~cm}$ ). After EBRT (CCRT or exclusive RT, $n=432$ ), 310 (72\%) patients received utero-vaginal brachytherapy, 56 cases (13\%) received external four fields RT at a dose of 24 Gy and 18 (4\%) received adjuvant surgery. 


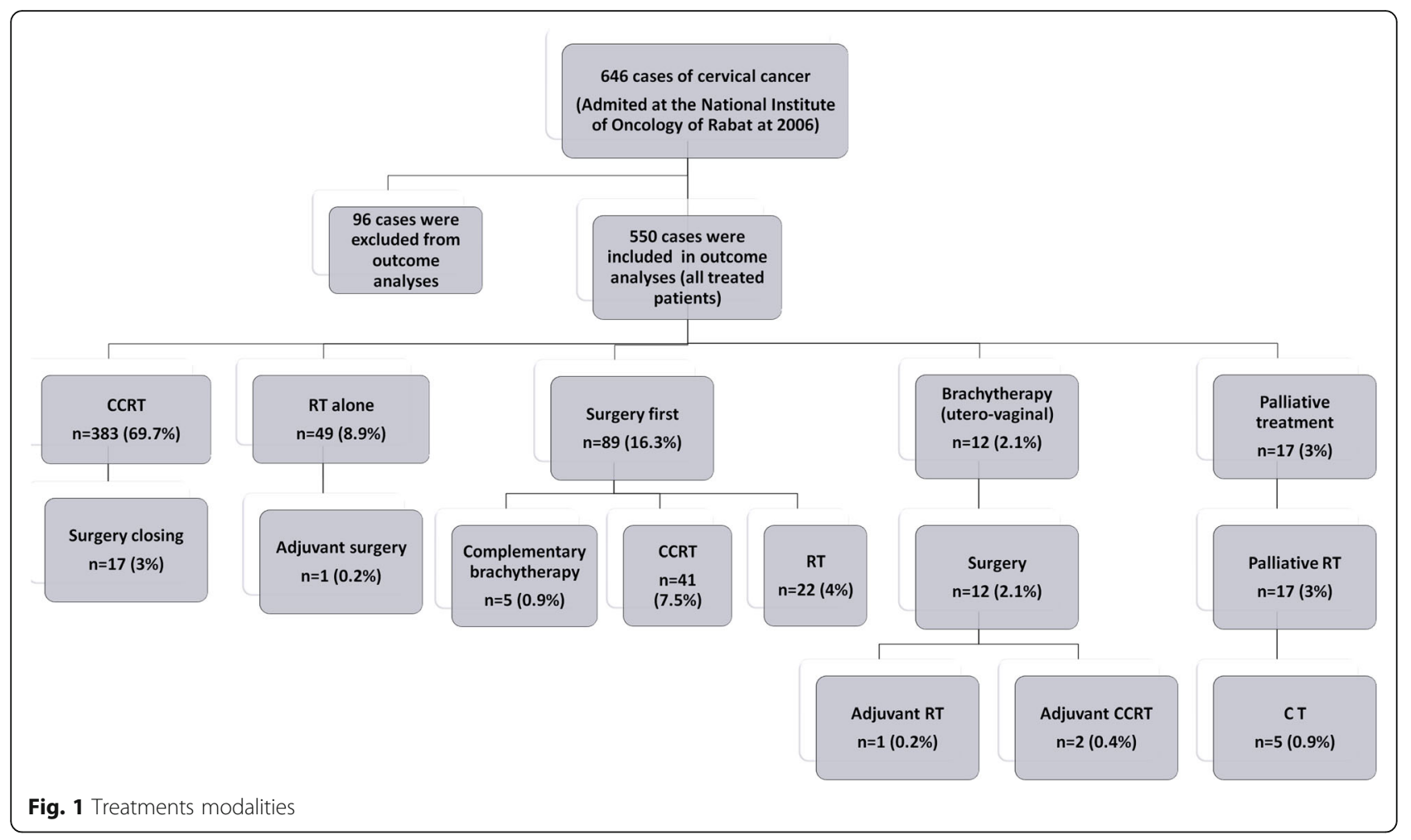

Unfortunately, 48 patients (11\%) did not receive complementary treatment. Three hundred thirteen patients presented with stage IIB distal or IIIB, 213 among them received a complementary parametrial dose $(9$ Gy $[3 \times 3 \mathrm{~Gy}]$ or $10 \mathrm{~Gy}[5 \times 2 \mathrm{~Gy}]$ ), 46 patients received four additional radiation fields at a dose of 24 Gy (2 Gy per fraction), and 54 patients did not receive complementary parametrial dose. Among 137 patients who had suspicious pelvic lymph node on imaging, 102 received complementary dose of RT, while 35 patients did not receive lymph node complementary dose. Nine of 10 patients who have para-aortic lymph node received a complementary dose of 10-10.8 Gy (1.8-2Gy per fraction). A total of 81 patients did not complete their treatment (lost to follow up).

Surgery was the initial treatment of 89 cases $(16.3 \%)$, 68 of them (85\%) received adjuvant treatment: CCRT in 41 cases, RT in 22 cases, and brachytherapy in 5 cases. Twelve cases received preoperative brachytherapy followed by surgery (2.1\%), 1 of them received adjuvant $\mathrm{RT}$, and 2 patient received adjuvant CCRT.

Neoadjuvant chemotherapy was not a standard treatment in our institution, and was indicated in only 20 patients. Adjuvant chemotherapy was administered in 2 patients; in one case after surgery (stage IB1), and in a second case after RT (stage IIA).

Palliatives treatments were administered in 17 patients and were based on palliative RT in 12 cases and palliative RT plus palliative CT in 5 cases.

\section{Toxicities}

Table 3 shows the frequency of acute toxicities potentially associated with CCRT. Gade 3 and 4 anemia and neutropenia were observed in 8.3 and $4 \%$, respectively. Renal failure was showed in only $0.5 \%$ of cases.

\section{Outcomes}

Patients who received at least one treatment $(n=550)$ were included in the efficacy analysis.

\section{Response to treatments}

Table 4 shows the response to treatments at 3-months.

\section{Overall survival}

At 60 months median follow up, 160 deaths had been reported. The probability of 5 year overall survival was $63.2 \%$ (Fig. 2a).

\section{Progression free survival}

At 60 months median follow-up, 175 patients developed recurrence, local recurrence in $22.7 \%$ of the cases $(n=125)$ and metastatic recurrence in $13.8 \%$ of the cases $(n=74)$ (bone metastases in 26 cases [35.1\%], lung in 13 cases [17.5\%], peritoneal in 10 cases [13.5\%] and hepatic in 9 cases [12.2\%]). The probabilities of LRRFS and PFS at 5 years were 79.1, and $60.7 \%$, respectively (Fig. $2 \mathrm{~b}$ and c). 
Table 3 Acute toxicities in patients treated with CCRT $(n=425)$

\begin{tabular}{cll}
\hline & Number of patients & Percent \\
\hline Anemia & 113 & \\
Grade 1 & 78 & $26.6 \%$ \\
Grade 2 & 31 & $18.3 \%$ \\
Grade 3 & 4 & $7.3 \%$ \\
Grade 4 & & $1 \%$ \\
Neutropenia & 51 & \\
Grade 1 & 21 & $12 \%$ \\
Grade 2 & 28 & $5 \%$ \\
Grade 3 & 2 & $6.5 \%$ \\
Grade 4 & 2 & $0.5 \%$ \\
Renal failure & & $0.5 \%$ \\
\hline
\end{tabular}

\section{Locoregional recurrences}

Locoregional recurrences occurred in $22.7 \%$ of the cases, and metastasis recurrence occurred in $13.8 \%$ of the cases. Locoregional recurrences were associated with metastatic evolution in $4.3 \%$ of cases. $82.9 \%$ of relapses occurred in the first 2 years after treatment and $63.4 \%$ of recurrences are centro-pelvic.

\section{Prognostic factors}

In univariate analysis (Fig. 3 [a to o]), we identified five poor prognostic factors with a statistically significant impact on the disease: tumor size, clinical stage, lymph node involvement, hemoglobin level less than $12 \mathrm{~g} / \mathrm{dl}$ during RT, and absence of response to radiotherapy (46 Gy). Tumor size (greater than $4 \mathrm{~cm}$ ) was a poor prognostic factor that affected significantly OS $(p<0.0001)$, PFS ( $\mathrm{p}<0.0001)$ and LRRFS $(p=0.013)$. Clinical stage: Clinical stage affected significantly the prognosis of our patients: OS $(p<0.0001)$, PFS $(p<0.0001)$ and LRRFS $(p=0.007)$. Lymph node involvement (suspected on imaging) was a statistically poor prognostic factor influencing OS

Table 4 Response to treatments at 3-months

\begin{tabular}{ll}
\hline Treatment & Response \\
\hline Surgery first $(n=89)$ & R0 resection (93.2\%) \\
CCRT $(n=363)$ & ORR (91\%) \\
& CR $(65 \%)$ \\
& PR (26\%) \\
& PD $(6.5 \%)$ \\
& Unknown response $(2.5 \%)$ \\
RT $(n=48)$ & ORR (81\%) \\
& CR (79\%) \\
& PR (2\%) \\
& PD (19\%)
\end{tabular}

CCRT Concurrent chemoradiotherapy, ORR Objective response rate, $C R$ complete response, $P R$ Partialresponse, $P D$ Progression disease, $R T$ radiotherapy

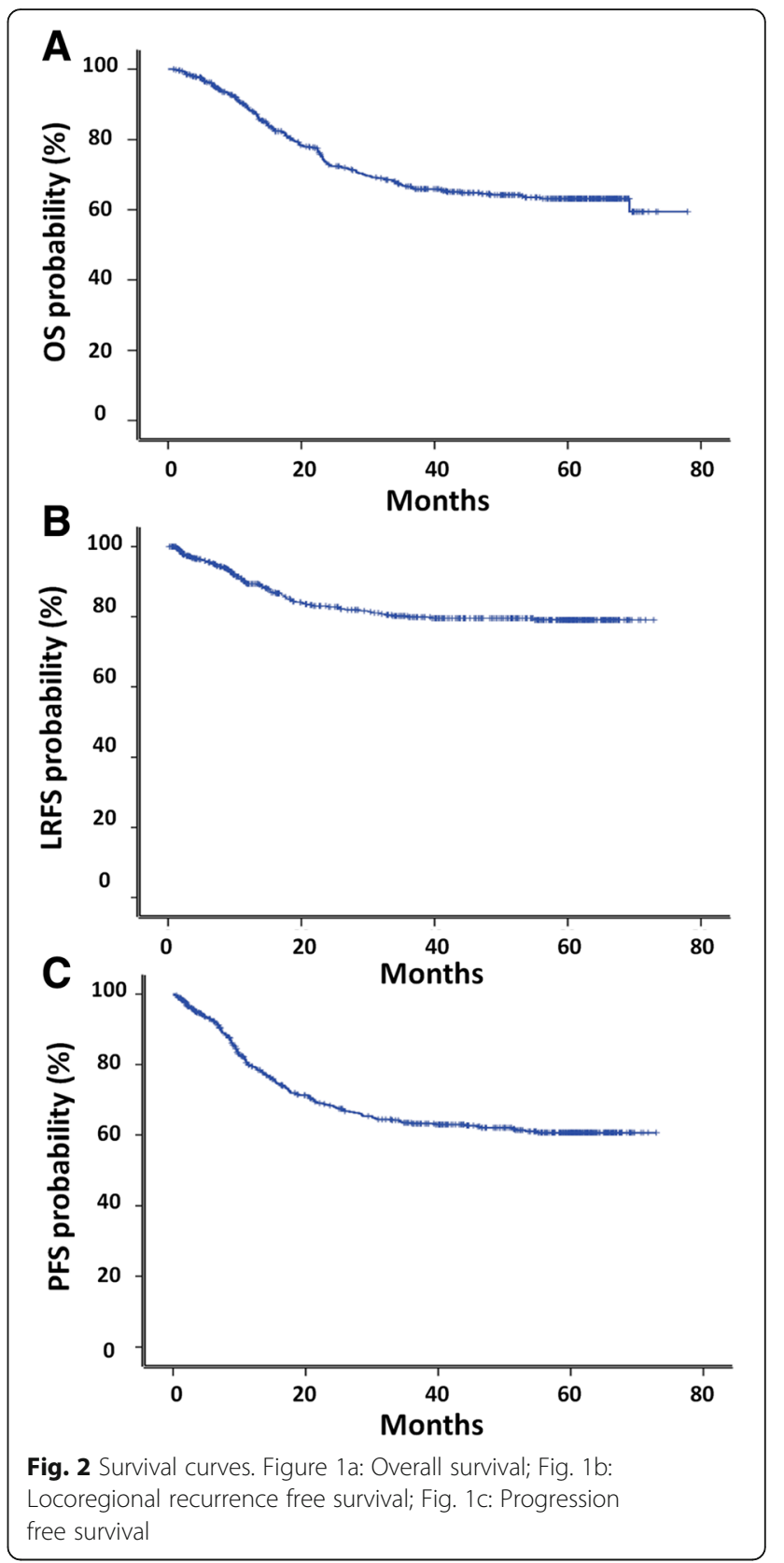

$(p=0.008)$, PFS $(p=0.038)$ and LRRFS $(p=0.008)$. Anemia during RT affected all parameters of survival: OS $(p=0.016)$, PFS $(p=0.008)$ and LRRFS $(p=0.009)$. Absence of response after a dose of 46 Gy of RT influencing $\operatorname{OS}(p<0.0001)$, PFS $(p<0.0001)$ and LRRFS $(p=0.075)$.

Multivariate analysis performed by using cox proportional hazard model showed that response to RT and clinical stage are two independent factors influencing outcome of patients with cervical carcinoma in our population. Absence of response to RT was a prognostic factor influencing significantly and independently PFS $(p=0.001)$ and OS $(p=0.001)$. Clinical stage was a 


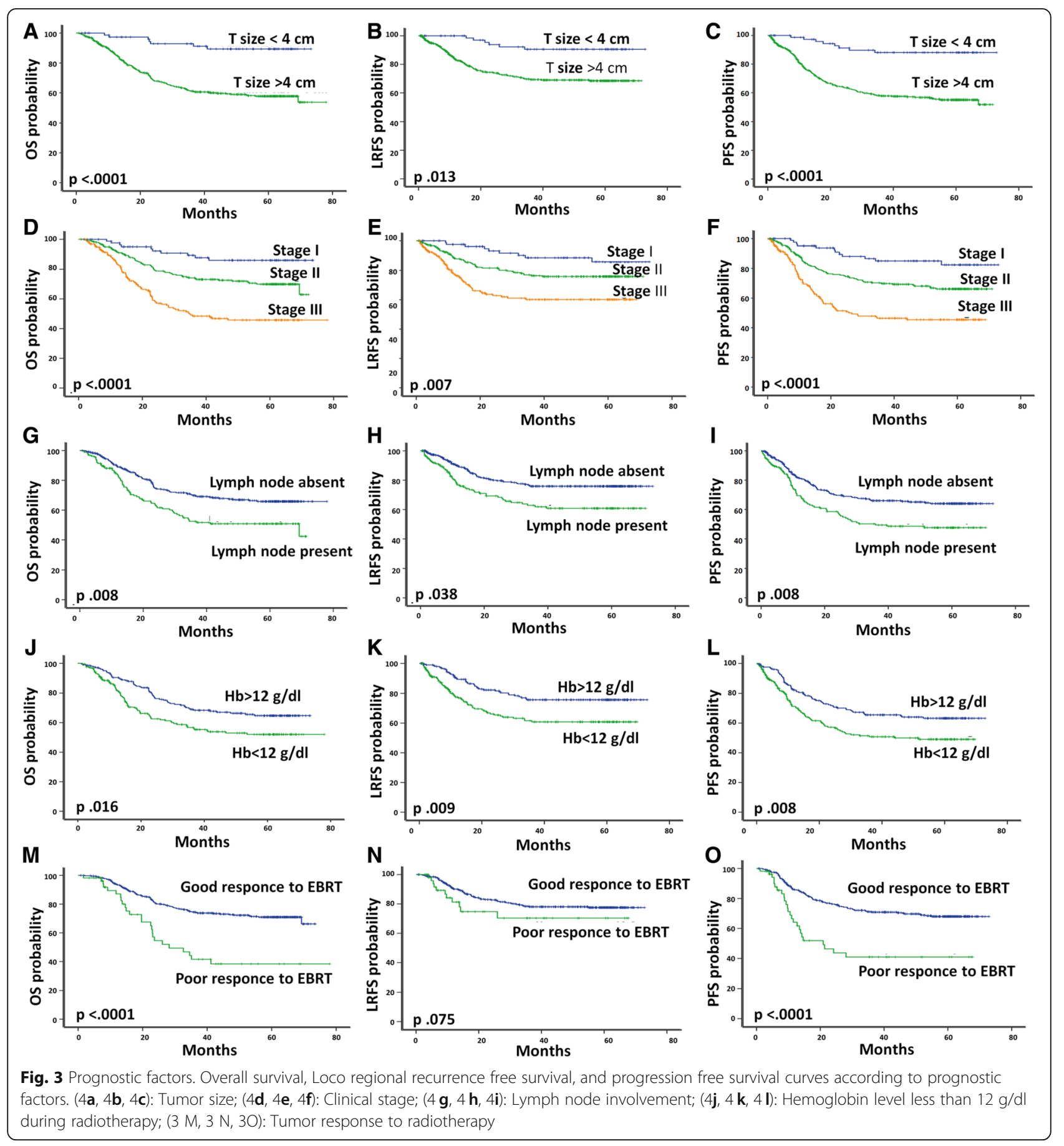

prognostic factor affecting LRRFS $(p=0.09)$, PFS $(p=$ $0.033)$ and $\mathrm{OS}(p=0.012)$.

\section{Discussion}

We conducted a retrospecive study to evaluate the epidemiology and outcome of cervical carcinoma in Morocco. To our best knowledge, our study was the first published study evaluating the epidemiological characteristics and prognostic of cervical cancer in our country. We found the predominance of locally advanced stages, so the diagnosis was most often made at advanced stages in $88 \%$ of cases (IB2, II, III and IV in $3.7 \%, 6.3 \%, 36.9 \%, 39 \%, 2 \%$ respectively). The majority of patients $(69.7 \%)$ received CCRT. At 5 years, PFS and OS were 63.2 and $60.7 \%$ respectively. Outcomes of our patients with cervical carcinoma are influenced by response to RT and clinical stage who are two independent factors retained in multivariate analysis. After RT, 
patients with clinical response to radiotherapy had a higher rate of PFS and OS.

One potential drawback of our study was the high number of lost to follow up patients before management. The inclusion of these women may have affected the overall survival from cervical cancer. This is due to low socio-economic level of most cases included in our institute. These patients have been excluded from the efficacy analyses. In addition, we showed a high rate of locoregional recurrences $(22.7 \%)$ which may be due mainly to the delay of diagnosis, and secondarily due to the quality of treatments received; surgery, lymph node dissection, radiotherapy, spreading of radiation which is very large in most cases (median 84 days), and radiation - brachytherapy period which exceeded 6 weeks in all cases. Among the strength of our study : the large sample size and the standardized treatments available in our institute (surgery and or radiotherapy with or withouth chemotherapy and brachytherapy).

Our results have shown that cervical cancer in Morocco is diagnosed at advanced stages in $88 \%$ of the cases. Several retrospective studies have shown similar findings. In South American population $(n=190)$, stage distribution was the following: II and IIIB in $93.7 \%$ of cases. [8]. In the Korean series [9], we noted $43.8 \%$ of locally advanced stages IB2-IV. However, in Europe, cervical cancer, was diagnosed mainly at localized stages IB; $73.4 \%$ in France [10]. In an Asiatic series from investigator in Beijing $(n=1399)$ [11], there is a predominance of localized stage I in $57.1 \%$. The discrepancy noted in the results of different series is due to socio-economic level on one hand and practice in another hand. Indeed, in industrialized countries screening policy exists, the frequency of advanced stages is small compared to that of precancerous lesions and localized forms. While in developing countries, cervical cancer is often discovered at advanced stages due to the lack of screening policy.

Outcomes of locally advanced tumors of cervix are improved since CCRT has become the standard of care for these stages, based on the report of several randomized clinical trials and metaanalyses [12]. This therapeutic modality is superior to RT alone in the rate of local control, survival without metastatic recurrence, PFS and OS. In our series, the majority of patients $(n=69.7 \%)$ received CCRT.

Five year OS of $63.2 \%$ among patients in our series was much better than that of patients treated in other part of Africa (sub-Saharan Africa); for example, 2 year overall survival observed among patients in a recent Kenyan series was less than $20 \%$ [13]. In addition, the 5 years OS in our study was comparable to that observed among patients in certain developed countries; in Canada 5 years survivals varied from 54 to $67 \%$ [14]; in England population, 5-year survival was 69.8 \% [15].
In a serie of cervical cancer in young Moroccan women, treated between 1980 and 1990, overall survival rate was only $41 \%$ at 5 years [5]. We can conclude that prognosis of our population has been improved since the date by introduction of CCRT as a standard treatment of advanced stages.

Five prognostic factors in our study population were associated with a statistically significant impact (in univariate analysis) on LRRFS, PFS and OS: tumor size, clinical stage, lymph node involvement, anemia with hemoglobin lower than $12 \mathrm{~g} / \mathrm{dl}$ during radiotherapy, and tumor response to RT (46 Gy). Significant prognostic factors in multivariate analysis (by Cox proportional hazard model) include response to RT influencing significantly PFS and OS, and clinical stage was a factor influencing LRRFS, PFS and OS. The main prognostic factors were clinical stage, tumor volume, lymph node metastases identified by lymphography and grade of histological differentiation. Clinical stage is clearly the most powerful determinant of outcome in most scientific papers [16-23].

\section{Conclusions}

Cervical cancer is a major health problem in Morocco due to the high incidence and to the frequent diagnosis at locally advanced stages. Therefore, the most used strategy in our center was CCRT. The outcomes of ourpatient has been improvedas compared to previous published Moroccan data in the 1990s. Significant prognostic factors in our study were the stage, and absence of response to EBRT. To reduce the global burden and mortality of cervical cancer, we should inform and educate women about risk factors and prevention, so we should start vaccines (HPV 16-18) to girls before the start of sexual activity and undertake an effective screening programs for women over 30 years old incorporating validated HPV DNA tests. Governments are challenged to firstly establish a policy of systematic screening with the objective of early detection of cervical cancer, and to obtain an acceptable rate of healing.

\section{Additional file}

Additional file 1: STROBE Statement-Checklist of items that should be included in reports of cohort studies. (PDF $18 \mathrm{~kb}$ )

\section{Abbreviations}

CCRT: Concurrent chemoradiotherapy; CR: Complete response; FIGO: International federation of gynecology and obstetrics; LRRFS: Locoregional recurrence free

survival; OR: Objective response; OS: Overall survival; PFS: Progression free survival; RT: Radiotherapy; SCCS: Quouamous cell carcinoma

\section{Acknowledgements}

We are very grateful to archives unit, and all members of National Institute of Oncology,who manage patients with cervical cancer, for their support, contributions and treatment. We would also like to thank all the women who participated in this study and their commitment in responding to our questions. 


\section{Funding}

Not applicable.

\section{Availability of data and materials}

Data will not be share in order to protect the participants' anonymity.

\section{Authors' contributions}

SE: conception and design, acquisition of data, analysis and interpretation of data, statistical analysis, literature review, drafting the manuscript and revising it critically for important intellectual content; Nl: conception and design, analysis and interpretation of data, statistical analysis, literature review, drafting the manuscript and revising it critically for important intellectual content, HEK : review of finale manuscript, TK : review of finale manuscript; HS : conception, design and revising it critically for important intellectual content, NB : conception, design and revising it critically for important intellectual content. All authors read and approved the final manuscript.

\section{Competing interests}

The authors declare that they have no competing interests.

\section{Conflict of interest}

All authors have declared no conflicts of interest.

\section{Consent to publication}

Not applicable.

\section{Ethics approval and consent to participate}

The ethical approval for the study was obtained from our ethics committee; the National Institute of Oncology ethics committee. Written informed consent was not required, however all patients provided there oral consent. The ethics committee approved the verbal informed consent procedure.

\section{Author details}

'Department of Radiotherapy, National Institute of Oncology, Mohammed V University, Rabat, Morocco. ${ }^{2}$ Medical Oncology, Cheikh Khalifa Ibn Zaid Hospital, Université Mohammed VI des Sciences de la Santé, Casablanca, Morocco. ${ }^{3}$ Department of Radiotherapy, Mohammed V Hospital, Mohammed $\checkmark$ University, Rabat, Morocco.

Received: 10 October 2014 Accepted: 6 September 2016

Published online: 13 September 2016

\section{References}

1. Jemal A, Bray F, Center MM, Ferlay J, Ward E, Forman D. Global cancer statistics. CA Cancer J Clin. 2011;61(2):69-90. doi:10.3322/caac.20107. Epub 2011 Feb 4.

2. Ahmedin J, Freddie B, Melissa M, et al. Global cancer statistics. Cancer J for Clin. 2011;61:69-90.

3. Schaffer P. Epidemiology of cervical and endometrial cancer. Bull Acad Natl Med. 1997;181:1347-62.

4. Tazi MA, Er-Raki A, Benjaafar N. Cancer incidence in Rabat, Morocco: 2006-2008. Ecancermedicalscience. 2013;7:338.

5. Acharki A, Sahraoui S, Benider A, et al. Cancer of the uterine cervix in young women. A retrospective study of 337 cases. Bull Cancer. 1997;84:373-8.

6. Mantel N, Haenszel W. Chi-square with one degree of freedom: extensions of the Mantel-Haenszel procedure. J Am Stat Assoc. 1963:58:690-700.

7. Cox DR. Regression models and life table. J R Stat Soc. 1972;34:187-220.

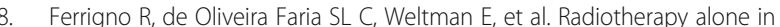
the treatment of uterine cervix cancer with telecobalt and low dose rate brachytherapy: retrospective analysis of results and variables. Int J Radiat Oncol Biol Phys. 2003;55:695-706.

9. Seol HJ, Ki KD, Lee JM. Epidemiologic characteristics of cervical cancer in Korean women. J Gynecol Oncol. 2014;25(1):70-4. Epub 2014 Jan 8.

10. Durand JC, Charvolin JY, Asselain B, et al. Association of radiotherapy and surgery in cervical malignancies at the early stage. Reprod Hum Horm. 1995;7:435-40.

11. Zhang JF, Wang T, Wu MH, et al. Present epidemiological status and clinical characteristics of cervical cancer in Beijing: a report of 1399 patients. Zhonghua Yi XueZaZhi. 2011:91:3058-61.

12. Resbeut M, Fondrinier E, Fervers B, et al. Standards, Options and Recommendations for the management of invasive cervical cancer patients (non metastastic). Bull Cancer. 2003;90:333-46.
13. Maranga IO, Hampson L, Oliver AW, et al. Analysis of factors contributing tothe low survival of cervical cancerpatients undergoing radiotherapy in Kenya. PLoS One. 2013;8:e78411.

14. Mahmud A, Brydon B, Tonita J, et al. A population-based study of cervix cancer: incidence, management and outcome in the Canadian province of Saskatchewan. Clin Oncol. 2011;23:691-5.

15. Profile of Cervical Cancer in England: incidence, mortality and survival. Sheffield: 2012.

16. Fyles AW, Pintilie M, Kirkbride $P$, et al. Prognostic factors in patients with cervix cancer treated by radiation therapy: results of a multiple regression analysis. Radiother Oncol. 1995:35:107-17.

17. Johnson DW, Cox RS, Billingham G, et al. Survival, prognostic factors, and relapse patterns in uterine cervical carcinoma. Am J Clin Oncol. 1983:6:407-15.

18. Kapp DS, Fischer D, Gutierrez E, et al. Pretreatment prognostic factors in carcinoma of the uterine cervix: amultivariable analysis of the effect of age, stage, histology and bloodcounts on survival. Int J Radiat Oncol Biol Phys. 1983;9:445-55.

19. Lanciano RM, Won M, Coia LR, et al. Pretreatment and treatment factors associated with improved outcome in squamous cell carcinoma of the uterine cervix: a final report of the 1973 and 1978 Patterns of Care studies. Int J Radiat Oncol Biol Phys. 1991;20:667-76.

20. Meanwell CA, Kelly KA, Wilson S, et al. Young age as a prognostic factor in cervical cancer: analysis of population based data from 10022 cases. Br Med J. 1988;296:386-91.

21. Perez CA, Grigsby PW, Nene SM, et al. Effect of tumor size on the prognosis of carcinoma of the uterine cervix treated with irradiation alone. Cancer. 1992;69:2796-806

22. Rutledge FN, Mitchell MF, Munsell M, et al. Youth as a prognostic factor in carcinoma of the cervix: a matched analysis. Gynecol Oncol. 1992;44:123-30.

23. Sigurdsson K, Hrafnkelsson J, Geirsson G, et al. Screening as a prognostic factor in cervical cancer: analysis of survival and prognostic factors based on Icelandic population data, 1964-1988. Gynecol Oncol. 1991;43:64-70.

\section{Submit your next manuscript to BioMed Central and we will help you at every step:}

- We accept pre-submission inquiries

- Our selector tool helps you to find the most relevant journal

- We provide round the clock customer support

- Convenient online submission

- Thorough peer review

- Inclusion in PubMed and all major indexing services

- Maximum visibility for your research

Submit your manuscript at www.biomedcentral.com/submit
Biomed Central 